\title{
Gergithoides Schumacher, 1915 in Vietnam, with two new species, and taxonomic notes on the genus (Hemiptera: Fulgoromorpha: Issidae)
}

\author{
Jérôme CONSTANT ${ }^{1, *}$ \& Hong-Thai PHAM ${ }^{2}$ \\ ${ }^{1}$ Royal Belgian Institute of Natural Sciences, O.D. Phylogeny and Taxonomy, Entomology, \\ Vautier Street 29, B-1000 Brussels, Belgium. \\ ${ }^{2}$ Vietnam National Museum of Nature, Vietnam Academy of Science and Technology, \\ 18 Hoang Quoc Viet Street, Hanoi, Vietnam. \\ *Corresponding author: jerome.constant@naturalsciences.be \\ ${ }^{2}$ Email: phamthai@,vnmn.vast.vn \\ ${ }^{1}$ urn:Isid:zoobank.org:author:6E6072A1-9415-4C8D-8E60-2504444DB290 \\ ${ }^{2}$ urn:1sid:zoobank.org:author:E34CB863-7E3B-4E8F-8738-B41C07D9F5F9
}

\begin{abstract}
Two new species of the genus Gergithoides Schumacher, 1915 (Issinae, Hemisphaeriini), G. gnezdilovi sp. nov. from Bidoup-Nui Ba National Park in Central Vietnam and G. nui sp. nov. from Pia-Oac National Park in North Vietnam, are described. These are the only species of the genus formally recorded from Vietnam to date. Habitus, details and male genitalia are illustrated and a distribution map is provided. Four females representing three or four additional species, known from females only, are mentioned and illustrated. Taxonomic and biogeographical updates based on a thorough review of the literature are proposed and discussed for G. carinatifrons Schumacher, 1915, G. rugulosus (Melichar, 1906) and G. undulatus Wang \& Che, 2003.
\end{abstract}

Keywords. Global Taxonomic Initiative, Annam, Tonkin, planthopper, Fulgoroidea.

Constant J. \& Pham H.-T. 2017. Gergithoides Schumacher, 1915 in Vietnam, with two new species, and taxonomic notes on the genus (Hemiptera: Fulgoromorpha: Issidae). European Journal of Taxonomy 296: 1-20. https://doi. org/10.5852/ejt.2017.296

\section{Introduction}

Schumacher (1915) described the genus Gergithoides to accommodate one new species from Taiwan: G. carinatifrons Schumacher, 1915 with one variety, uniformis. The year after, Matsumura (1916) described the genus Daruma to accommodate one new species from Taiwan: D. nitobei Matsumura, 1916. The name Daruma was replaced by Darumara by Metcalf (1952), because it was preoccupied by Daruma Jordan \& Starks, 1904, a fish genus in the family Cottidae (Pisces: Actinopterygii: Scorpaeniformes). Darumara was proposed as a junior synonym of Gergithoides, under the misspelled name "Darma", by Ishihara (1965a), who also proposed "Darma" (= Darumara) nitobei as a junior synonym of $G$. carinatifrons. Hori (1969) followed this view but Chan \& Yang (1994) did not take 
Ishihara's (1965a) work into account and still considered Darumara as a separate genus and D. nitobei as a good species. Gnezdilov (2009) synonymized again Darumara under Gergithoides, and D. nitobei under G. carinatifrons, without any reference to Ishihara's (1965a) previous action, and his view was followed by subsequent authors (Rahman et al. 2012; Chen et al. 2014).

Gergithoides carinatifrons was mentioned by Esaki (1932) and Kato (1933) in works treating the Japanese entomological fauna, and hence recorded from Japan by Metcalf (1958). It remains, however, unclear whether the species was actually recorded from Japan or if it was mentioned because, at that time, Taiwan was under Japanese rule (1895-1945), as Kato (1933) stated for the species "in mountainous areas in Taiwan, not abundant", but did not formally mention Japan (M. Hayashi pers. comm., May 2016). Ishihara (1965a) gave the first distribution data for Japan (Shikoku), and Hori (1969) added the Ryukyus (Okinawa, Ishigaki and Iriomote Islands), and illustrated the male genitalia and two specimens, but failed to indicate the origin of the specimens figured (he examined specimens from Taiwan as well as from Japan). Chan \& Yang (1994) also mentioned the species from Taiwan and Japan. They provided a redescription and illustrated the male genitalia based on Taiwanese material. The species was also erroneously recorded from South Korea by Kwon \& Huh $(1995,2001)$ based on misidentified specimens (Rahman et al. 2012) which were later described as a separate species, G. jejudoensis Rahman, Kwon \& Suh, 2012. Additional records of the species from China were given by Che et al. (2003) (Hainan) and by Chen et al. (2014) (Guizhou). The latter record was based on the examination of female specimens only.

Jacobi (1944) added one species to the genus by transferring Gergithus rugulosus Melichar, 1906 into Gergithoides. The species was described from Malaysia (Melichar 1906) and listed from Fukien (= Fujian), China by Jacobi (1944). It was also later mentioned from China by Che et al. (2003), based on male specimens from Fujian and female specimens from Guangxi, Sichuan and Yunnan. Chen et al. (2014) added the province Guizhou to the list of Chinese records based on males and females, and illustrated the male genitalia based on Chinese material.

Recently, Che et al. (2003) added two species, G. gibbosus Chou \& Wang, 2003 from Hainan and G. undulatus Wang \& Che, 2003 from Guangxi and Hainan. The holotype of the latter species is a male from Guangxi, while all paratypes are female specimens from Hainan. The male genitalia were illustrated for both species. Additional recent data from the type locality were given for G. gibbosus by Chen et al. (2014), who also illustrated the habitus and male genitalia of a specimen attributed to G. undulatus originating from Hainan.

Finally, Chen et al. (2014) described G. caudospinosus Chen, Zhang \& Chang, 2014 from Guizhou.

The genus currently contains 6 species and one subspecies (Che et al. 2003; Rahman et al. 2012; Gnezdilov et al. 2014; Chen et al. 2014) distributed from Malaysia to China, Taiwan, South Korea, Japan and Vietnam (Bourgoin 2016).

The genus was first mentioned from Vietnam by Gnezdilov et al. (2014) based on a single female collected in Bidoup-Nui Ba National Park, Lam Dong Province.

The study of the material of Issidae collected during fieldwork in the frame of our Global Taxonomic Initiative project "A Step further in the Entomodiversity of Vietnam" and of unmounted specimens in the collections of the Vietnam National Museum of Nature revealed 4 or 5 additional species for the country. The description of Gergithoides species requires the characters of the male genitalia and unfortunately males are available for only two species, which are both new to science. 
The present paper aims at describing the two new species and giving an overview of the other Vietnamese material currently available. We also provide a critical review of a number of pending taxonomic issues within the genus.

\section{Material and methods}

The specimens were captured by hand using small transparent vials with which they were slowly covered or by sweeping the lower vegetation and bushes in the forest. The specimen illustrated alive was transferred in a mesh pop up cage (Exo Terra Explorarium ${ }^{\circledR}$ ) and photographed with a Sony DSC-H300 camera. Although not completely natural, this system has the great advantage of minimizing the risk of escaping.

The genitalia were extracted after boiling the abdomen in a $10 \%$ solution of potassium hydroxide $(\mathrm{KOH})$ at about $100^{\circ} \mathrm{C}$. Some drops of saturated alcoholic Chlorazol black solution were added for contrast (Carayon 1969). The pygofer was separated from the abdomen and the aedeagus dissected with a needle blade for examination. The organs were then placed in glycerine for preservation in a vial attached to the pin of the corresponding specimen. The metatibiotarsal formula gives the number of spines on (side of metatibia) apex of metatibia/apex of first metatarsus/apex of second metatarsus.

The classification follows Wang et al. (2016).

The measurements were taken as in Constant (2004) and the following acronyms are used:

$\mathrm{BF}=$ maximum breadth of the frons

$\mathrm{BTg}=$ maximum breadth of the tegmen

$\mathrm{BV}=$ maximum breadth of the vertex

$\mathrm{LF}=$ length of the frons in median line

$\mathrm{LTg}=$ maximum length of the tegmen

$\mathrm{LT}=$ total length (apex of head to apex of tegmina)

$\mathrm{LV}=$ length of the vertex in median line

Photographs were taken with a Canon EOS 700D camera equipped with a Tamron DI SP $90 \mathrm{~mm}$ macro lens, staked with CombineZ software and optimized with Adobe Photoshop CS3. Observations were done with a Leica MZ8 stereo microscope.

The Chinese material was not available for study and we based our observations for $G$. carinatifrons Schumacher, 1915, G. rugulosus (Melichar, 1906) and G. undulatus Wang \& Che, 2003 on the published illustrations (see also FLOW: http://hemiptera-databases.org/flow/?page=explorer\&db=flow\&lang=en

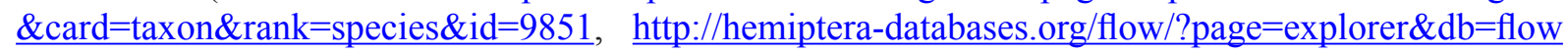
$\underline{\text { \&lang }=\text { en\&card=taxon\&rank }=\text { species } \& \mathrm{id}=9852 \text { and } \mathrm{http}: / \text { hemiptera-databases.org/flow } / \text { page }=\text { explo }}$ rer\&db=flow\&lang $=$ en\&card=taxon\&rank $=$ species\&id $=16115$ ).

Acronyms used for the collections:

MMBC $=$ Moravske Museum, Brno, Czech Republic

MNHN $=$ Museum national d'Histoire naturelle, Paris, France

NHRS $=$ Naturhistoriska riksmuseet, Stockholm, Sweden

RBINS = Royal Belgian Institute of Natural Sciences, Brussels, Belgium

VNMN = Vietnam National Museum of Nature, Hanoi, Vietnam

Original labels are quoted verbatim within square brackets. 


\title{
Results
}

\author{
Class Hexapoda Blainville, 1816 \\ Order Hemiptera Linnaeus, 1758 \\ Suborder Auchenorrhyncha Duméril, 1806 \\ Infraorder Fulgoromorpha Evans, 1946 \\ Superfamily Fulgoroidea Latreille, 1807 \\ Family Issidae Spinola, 1839 \\ Subfamily Issinae Spinola, 1839 \\ Tribe Hemisphaeriini Melichar, 1906 \\ Subtribe Hemisphaeriina Melichar, 1906
}

Genus Gergithoides Schumacher, 1915

Gergithoides Schumacher, 1915: 126. Type species: Gergithoides carinatifrons Schumacher, 1915 by monotypy.

Daruma Matsumura, 1916: 103 (preoccupied). Type species: Daruma nitobei Matsumura, 1916, by original designation. Synonymized by Ishihara (1965a: 208) under the erroneous spelling "Darma".

Darumara Metcalf, 1952: 227. New name for Daruma Matsumura, 1916. Synonymized by Gnezdilov (2009: 85) [erroneous: already synonymized by Ishihara (1965a)].

Darma Ishihara, 1965a: 208. Misspelling of Daruma.

We follow the definition of the genus given in the key to the genera of Hemisphaeriini proposed by Sun et al. (2012), with the following distinctive set of characters: (1) posterior wing longer than half length of tegmen; (2) frons with complete median carina; (3) lateral margins of frons not elevated and (4) a row of tubercles along lateral margin of frons.

\section{Note}

Ishihara (1965a) was the first to propose Daruma as a junior synonym of Gergithoides, although he should have used the name Darumara as proposed by Metclaf (1952). It seems that Chan \& Yang (1994) were not aware of Ishihara's (1965a) synonymy, as they considered Gergithoides and Darumara as separate genera. More recently, Gnezdilov (2009) reinstated Ishihara's (1965a) view but erroneously stated that he proposed a new synonymy instead.

\section{Species included}

G. carinatifrons Schumacher, 1915

G. caudospinosus Chen, Zhang \& Chang, 2014

G. gibbosus Chou \& Wang, 2003

G. gnezdilovi sp. nov.

G. jejudoensis Rahman, Kwon \& Suh, 2012

G. $n u i$ sp. nov.

G. rugulosus (Melichar, 1906)

G. undulatus Wang \& Che, 2003

\section{Remarks}

The species of Gergithoides should be identified based on the comparison of the male genitalia with reliable illustrations. Considering the numerous pending issues regarding the identity of the species of Gergithoides, it is currently unwise to propose an identification key to the species. 


\section{Gergithoides gnezdilovi sp. nov. urn:1sid:zoobank.org:act:A727E4D8-CCB1-4572-B3DB-78DB3D9972C6}

Figs $1-2,5$

\section{Diagnosis}

G. gnezdilovi sp. nov. can be recognized by the spiral-shaped trispinose process of the phallobase.

\section{Etymology}

The species is dedicated to our colleague and friend Dr Vladimir M. Gnezdilov (St Petersburg, Russia), great specialist of the family Issidae.

\section{Type material}

\section{Holotype}

VIETNAM: ${ }^{\curvearrowright}$, dissected, right hind wing mounted, Fig. 1A-E [Coll. I.R.Sc.N.B., Vietnam, Lam Dong prov., Bidoup-Nui Ba N.P., $12^{\circ} 26^{\prime}$ N 108 $30^{\prime}$ E, 21-25.vii.2014, day coll., Leg. J. Constant \& J. Bresseel, GTI Project, I.G.: 32.779] (RBINS).

\section{Description}

MeAsurements and Ratios. $\mathrm{LT}: \hat{\jmath}(\mathrm{n}=1): 5.2 \mathrm{~mm}$. $\mathrm{LTg} / \mathrm{BTg}=2.0 ; \mathrm{BV} / \mathrm{LV}=1.65 ; \mathrm{LF} / \mathrm{BF}=1.2$.

HEAD (Fig. 1A, C-D). Vertex broader than long in midline, brown with margins carinate and yellowish; in dorsal view, anterior margin convex, posterior one concave and lateral converging anteriorly; disc excavate, with obsolete tubercles. Side of head yellowish brown. Frons elongate and rugulose, brown; median carina yellowish, extending from dorsal margin down to level of base of eyes; row of yellowish tubercles along dorsal and lateral margins extending to level of base of eyes; lateral margins yellowish under eyes. Fronto-clypeal suture marked with yellowish colour at angles. Clypeus brown, elevated medially. Scape short, ring-shaped, black; pedicel bulbous, brown. Labium brown, with last segment longer than broad and shorter than penultimate.

Thorax (Fig. 1A, C). Brown. Pronotum very short, with median carina, and anterior and posterior margins carinate; disc concave; row of yellowish tubercles along anterior margin extending on paranotal fields to level of base of eyes; another oblique row of 3 yellowish tubercles on each side of disc, parallel to anterior margin. Mesonotum short, slightly coriaceous, with obsolete median carina and obsolete impressed point on each side of disc; transverse carina along anterior margin yellowish; 4-5 yellowish tubercles grouped at each external angle; yellowish spot on each side of scutellum; apex of scutellum marked with black. Tegulae brown.

Tegmina (Fig. 1A, C). Strongly convex; broader than long when taken together in dorsal view; impressed at basocostal angle; subcoriaceous with dense reticulum of slightly raised veins and veinlets; main veins barely distinct basally; beige with broad transverse dark brown band at proximal third; small black spot in middle of sutural margin.

Hind wings (Fig. 1E). Brown, unilobed, with veins darker, slightly shorter than tegmina. Venation reticulate, with main longitudinal veins distinct basally $(\mathrm{C}, \mathrm{ScP}+\mathrm{R}, \mathrm{MP}, \mathrm{CuA})$; numerous cross-veinlets. Anal area absent. Costal and cubital margins slightly sinuate, distal margin rounded.

Legs (Fig. 1A-D). Elongate and slender, yellow-brown with dark brown line along externoventral margin of femora. Onychium of pro- and mesotarsi, apex of tibiae and of lateral spines of metatibiae dark brown. Posterior tibiae with 2 lateral spines on apical $1 / 3$ and 6 apical spines.

Metatibiotarsal Formula. (2) 6/9/2. 


\section{Male genitalia}

Pygofer higher than broad and with posterior margin strongly rounded, with base sinuate in lateral view (Fig. 2A); ventral margin rounded in lateral view (Fig. 2A). Gonostyli (Fig. 2A, C) elongate in lateral view, emarginate dorsally at base of capitulum; capitulum well developed, elongate and projecting dorsointernally; with small tooth on dorsal margin and a basolateral laminate process with anteroventral hook; convex externally at base of capitulum (Fig. 2C). Anal tube (Fig. 2A-B) 1.25 times as long as broad, slightly curved ventrally in lateral view, dorsoventrally flattened, with sides broadly rounded, sinuate on apical third, and apicolateral angles roundly projecting ventroposteriorly. Aedeagus strongly
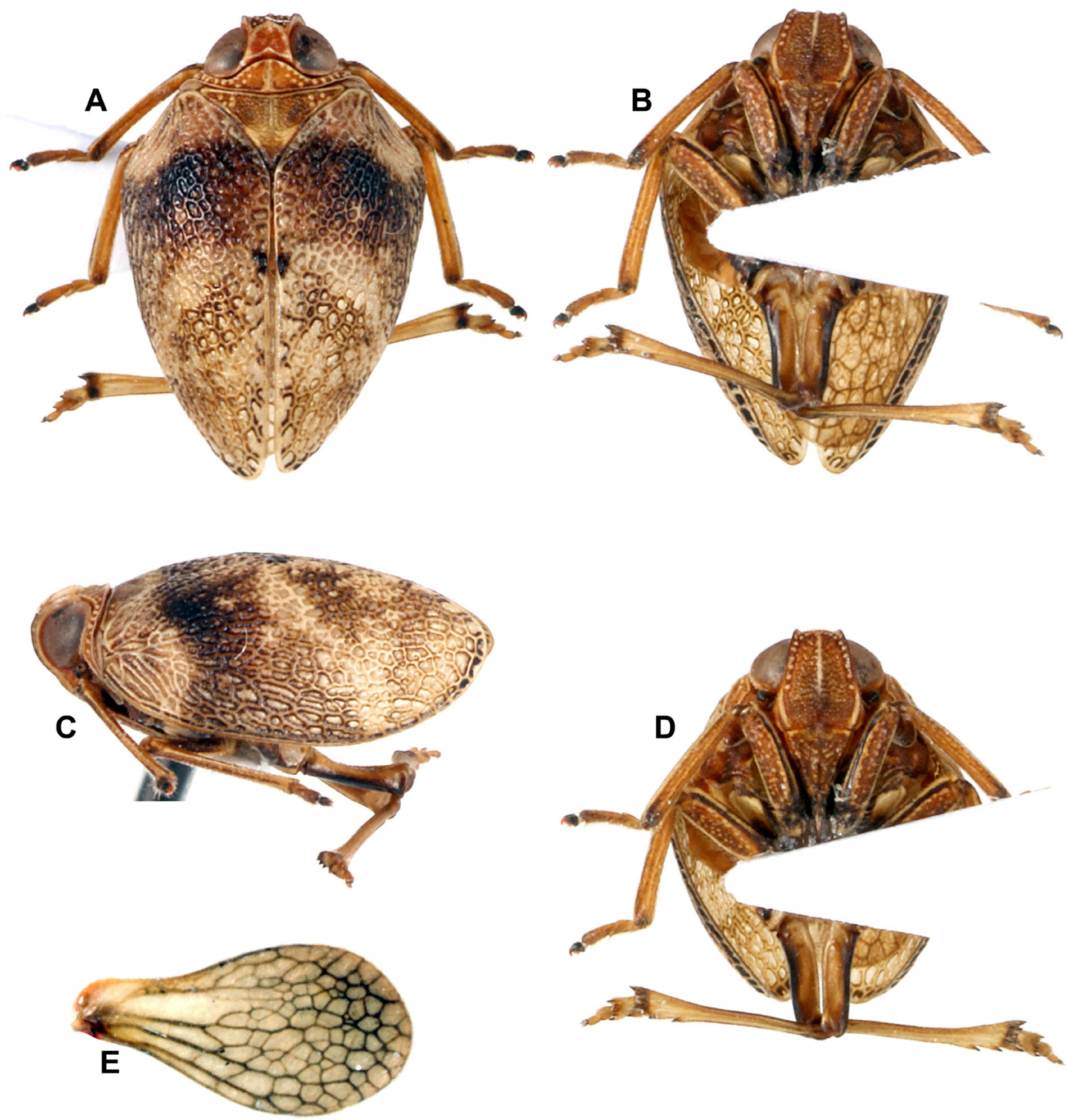

Fig. 1. Gergithoides gnezdilovi sp. nov., holotype, ô, total length: $5.2 \mathrm{~mm}$. A. Habitus, dorsal view. B. Habitus, ventral view. C. Habitus, lateral view. D. Habitus, normal view of frons. E. Right hind wing. 

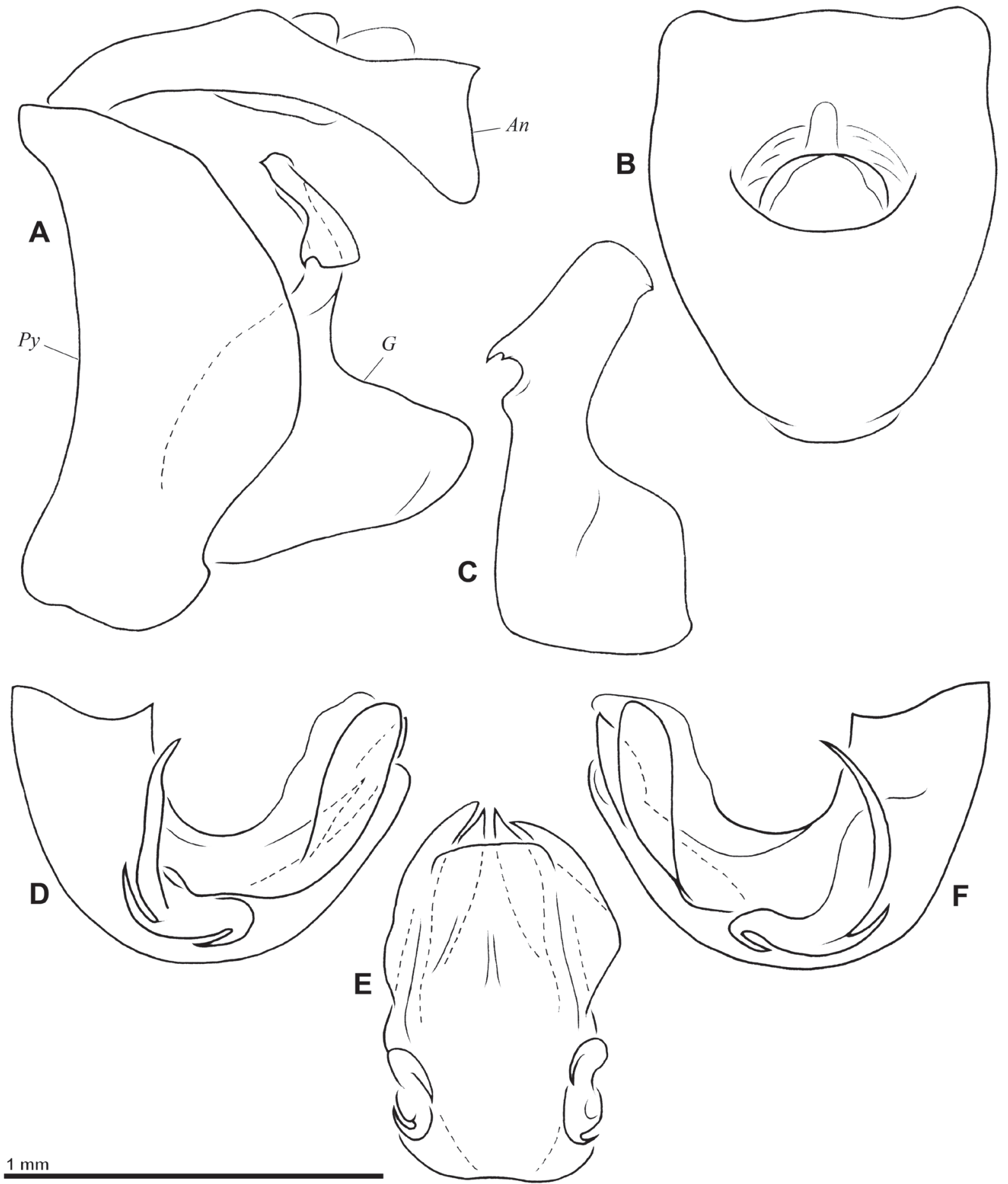

Fig. 2. Gergithoides gnezdilovi sp. nov., Ô, genitalia. A. Pygofer, anal tube and gonostylus, left lateral view. B. Anal tube, dorsal view. C. Left gonostylus, posterior view. D. Aedeagus, left lateral view. E. Aedeagus, posteroventral view. F. Aedeagus, right lateral view. Abbreviations: $A n=$ anal tube; $G=$ gonostylus; $P y=$ pygofer. 
curved posterodorsally, rather simple (Fig. 2D, F). Phallobase with lateral process at basal half showing 3 spines; posterior spine hooked ventroanteriorly, ventroanterior spine curved dorsally and anterodorsal spine longer, projecting dorsally (Fig. 2E-F); phallobase with laminate process on each side, with right one projecting slightly further laterally than left one (Fig. 2D-F) and 2 median processes pointed apically (Fig. 2E). Ventral lobe of phallobase broad and truncate dorsally, slightly oblique apically (Fig. 2E).

\section{Biology}

G. gnezdilovi sp. nov. was collected at the end of July on lower vegetation, in moist evergreen mountain forest at an altitude around $1600 \mathrm{~m}$ a.s.1.

\section{Distribution}

The species is currently recorded only from Bidoup-Nui Ba National Park, Lam Dong Province (Fig. 5).

Gergithoides nui sp. nov. urn:1sid:zoobank.org:act:3FE5C1D7-90AD-47E6-9F08-3D1E83A3E792

Figs $3-5$

\section{Diagnosis}

Gergithoides nui can be recognized by (1) the shape of the lateral process of the phallobase, with posterior spine strongly hooked anteroventrally and anteroventral spine strongly curved dorsally and elongate, (2) the ventral lobe of the phallobase, with dorsal margin emarginate on each side and indentated in middle, and (3) median posterior processes of phallobase pointed apically, and laterally emarginate subapically.

\section{Etymology}

"Nui" is the Vietnamese word for mountain. It refers to the mountainous origin of the type specimens and is used as a noun in apposition.

\section{Type material}

\section{Holotype}

VIETNAM: Õ, dissected, right hind wing mounted, Fig. 3A-E [Coll. VNMN., Vietnam, Cao Bang prov., Pia Oac N.P., 10.viii.2012, Leg. H.T. Pham] (VNMN).

\section{Paratype}

VIETNAM: $1 \AA$, same data as holotype (RBINS).

\section{Description}

MEAsurements AND Ratios. $\mathrm{LT}: \hat{\partial}(\mathrm{n}=2): 5.3-5.4 \mathrm{~mm} . \mathrm{LTg} / \mathrm{BTg}=2.0 ; \mathrm{BV} / \mathrm{LV}=1.65 ; \mathrm{LF} / \mathrm{BF}=1.28$.

HEAD (Fig. 3A, C-D). Vertex broader than long in midline, brown with margins carinate; anterior margin convex, posterior one concave and lateral converging anteriorly; disc excavate, with obsolete tubercles. Side of head yellowish brown. Frons elongate and rugulose, brown; median carina yellowish, extending from dorsal margin down nearly to frontoclypeal suture; row of yellowish tubercles along dorsal and lateral margins, extending to level of base of eyes; lateral margins yellowish under eyes; lateral margin under eye and median carina on dorsal $1 / 3$ bordered with dark brown. Clypeus black-brown, elevated medially. Scape short, ring-shaped, black; pedicel bulbous, brown. Labium dark brown, with last segment longer than broad and shorter than penultimate.

Thorax (Fig. 3A, C). Brown. Pronotum very short, with median carina, and anterior and posterior margins carinate; disc concave; row of yellowish tubercles along anterior margin extending on paranotal 
fields to level of base of eyes; another oblique row of 3 yellowish tubercles on each side of disc, parallel to anterior margin. Mesonotum short, slightly coriaceous, with obsolete median carina and obsolete impressed point on each side of disc; transverse carina along anterior margin yellowish; 4-5 yellowish tubercles grouped at each external angle; yellowish suffused marking on each side of scutellum; apex of scutellum marked with black. Tegulae brown.

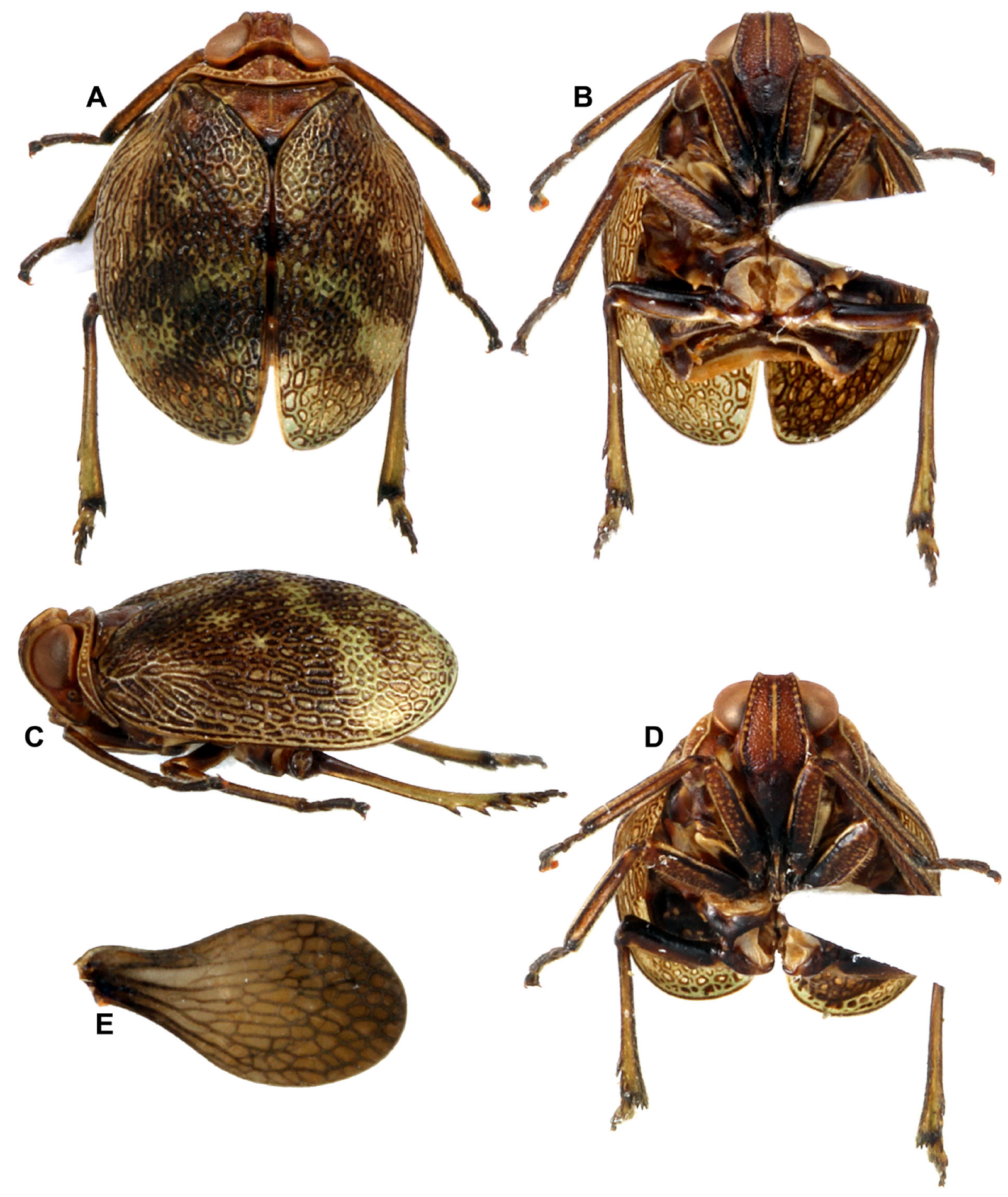

Fig. 3. Gergithoides nui sp. nov., holotype, $\widehat{\jmath}$, total length: $5.3 \mathrm{~mm}$. A. Habitus, dorsal view. B. Habitus, ventral view. C. Habitus, lateral view. D. Habitus, normal view of frons. E. Right hind wing. 

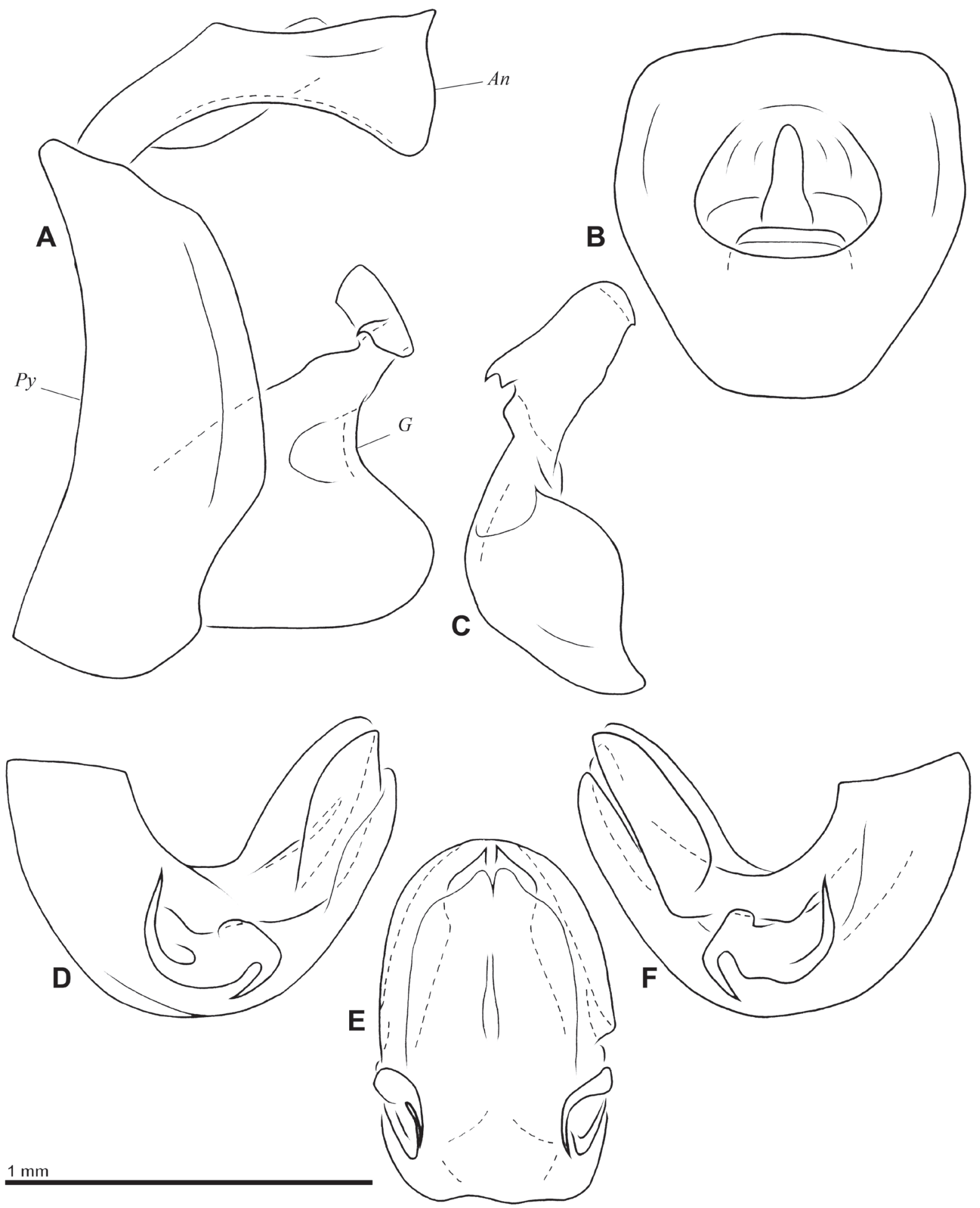

Fig. 4. Gergithoides nui sp. nov., Ô, genitalia. A. Pygofer, anal tube and gonostylus, left lateral view. B. Anal tube, dorsal view. C. Left gonostylus, posterior view. D. Aedeagus, left lateral view. E. Aedeagus, posteroventral view. F. Aedeagus, right lateral view. Abbreviations: $A n=$ anal tube; $G=$ gonostylus; $P y=$ pygofer. 


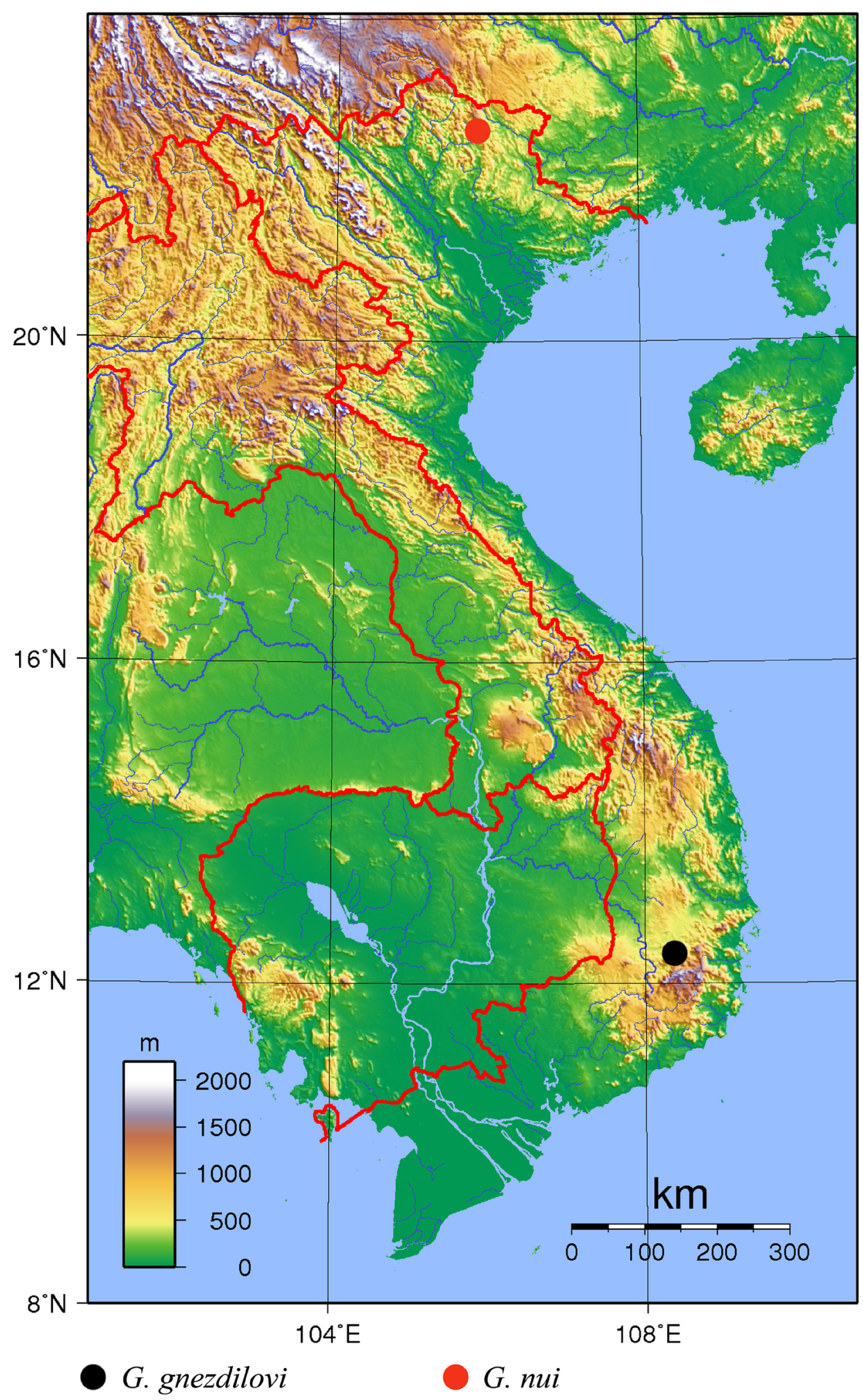

Fig. 5. Distribution map of Gergithoides gnezdilovi sp. nov. and G. nui sp. nov. 
TEgmina (Fig. 3A, C). Strongly convex; broader than long when taken together in dorsal view; impressed at basocostal angle; subcoriaceous with dense reticulum of slightly raised veins and veinlets; main veins barely distinct basally; pale green-brown, with brown to black irregular markings; broad transverse dark brown patch at apical third; small black spot in middle of sutural margin.

HIND wings (Fig. 3E). Brown, unilobed, with veins darker, slightly shorter than tegmina. Venation reticulate, with main longitudinal veins distinct basally $(\mathrm{C}, \mathrm{ScP}+\mathrm{R}, \mathrm{MP}, \mathrm{CuA})$; numerous cross-veinlets. Anal area absent. Costal and cubital margins sinuate, distal margin rounded.

LeGs (Fig. 3A-D). Elongate and slender, brown with black-brown line along externoventral margin of femora; black-brown line on ventral carinae of tibiae; base and apex of tibiae, apex of tarsi and apex of metatibial spines black-brown. Posterior tibiae with 2 lateral spines on apical $1 / 3$ and 6 apical spines.

Metatibiotarsal Formula. (2) 6/8-9/2.

\section{Male genitalia}

Pygofer higher than broad and with posterior margin slightly rounded, protruding laterally in median $1 / 2$, dorsal and ventral 1/4 sinuate in lateral view (Fig. 4A); ventral margin rounded in lateral view (Fig. 4A). Gonostyli (Fig. 4A, C) elongate in lateral view, emarginate dorsally at base of capitulum and depressed at level of emargination; capitulum well developed, elongate and projecting dorsointernally; with small tooth on dorsal margin and a basolateral laminate process with anteroventral hook; convex externally at base of capitulum (Fig. 4C). Anal tube (Fig. 4A-B) nearly as broad as long, curved ventrally in lateral view, dorsoventrally flattened, with sides subparallel on apical half; apicolateral angles roundly projecting ventrally. Aedeagus strongly curved posterodorsally, rather simple (Fig. 4D, F). Phallobase with lateral process at basal half showing 2 spines; posterior spine strongly hooked ventroanteriorly, ventroanterior spine elongate, strongly curved dorsally, and slightly sinuate apically (Fig. 4E-F); phallobase with laminate process on each side, with right one more developed and projecting slightly further laterally than left one (Fig. 4D-F) and 2 median processes pointed apically, and lateral margin sinuate anteapically (Fig. 4E). Ventral lobe of phallobase broad, with apical margin emarginate on each side and indentated medially (Fig. 4E).

\section{Biology}

Gergithoides nui sp. nov. was collected in August on lower vegetation, in moist evergreen tropical mountain forest at an altitude between 1600 and $1900 \mathrm{~m}$ a.s.1.

\section{Distribution}

The species is currently recorded only from Pia-Oac National Park, Cao Bang Province (Fig. 5).

\section{Gergithoides sp.}

Four additional female specimens of Gergithoides from Vietnam were also examined, representing maybe four additional species, or only three if the two specimens collected in Ba Vi National Park (Fig. 6A-C and D-F) are conspecific. This will have to be established by examination of the genitalia of corresponding males.

It appears interesting to list and illustrate those undescribed species to give a better view of the actual diversity and distribution of Gergithoides in Vietnam. 

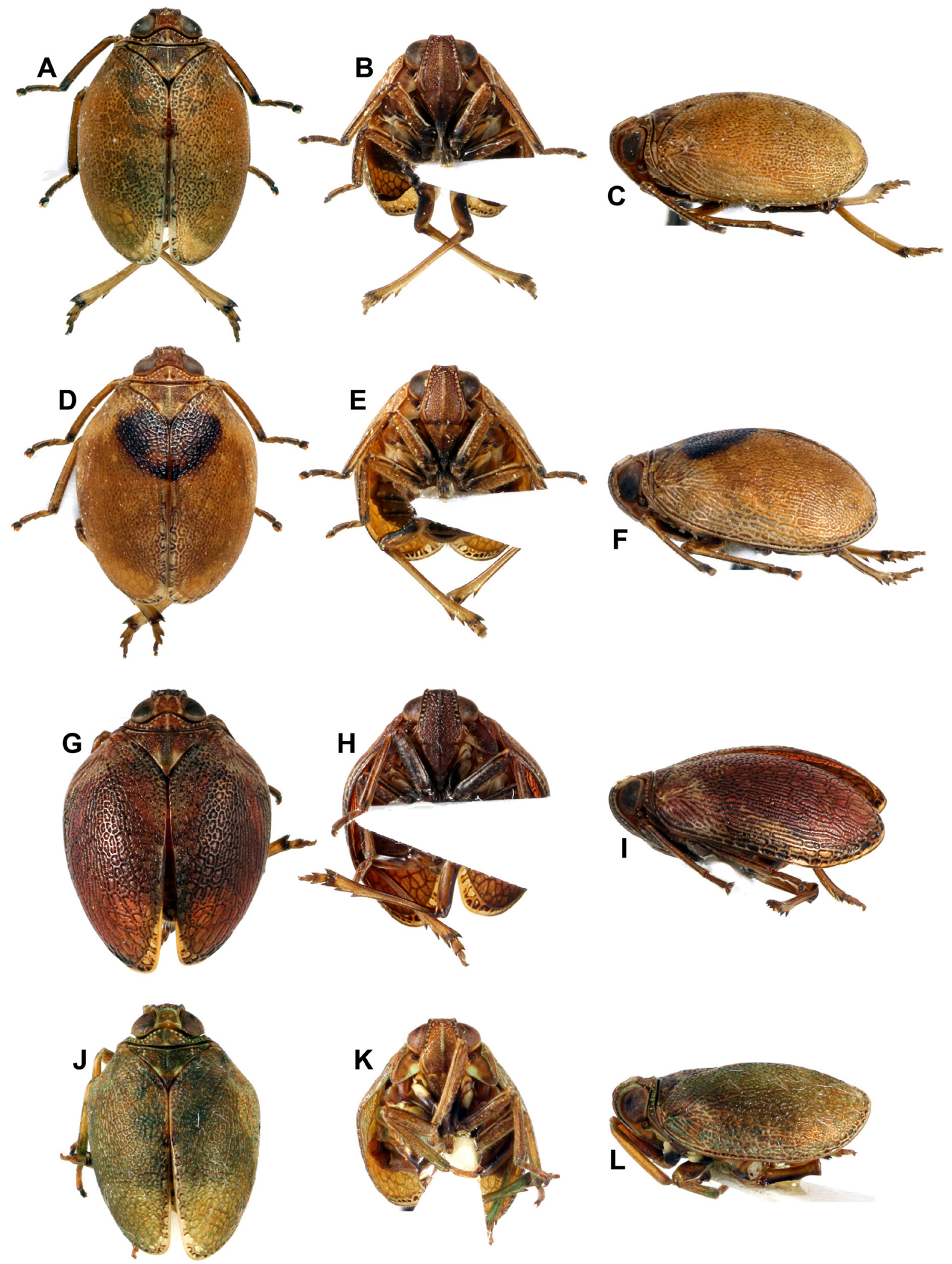

Fig. 6. Gergithoides $q \circ$, unidentified species from Vietnam. A-C. Specimen from Ba Vi National Park $(\mathrm{LT}=6.0 \mathrm{~mm})$. D-F. Specimen from Ba Vi National Park $(\mathrm{LT}=6.0 \mathrm{~mm})$. G-I. Specimen from Da Krong Nature Reserve $(\mathrm{LT}=6.6 \mathrm{~mm})$. J-L. Specimen from Bidoup-Nui Ba National Park (LT = $5.9 \mathrm{~mm}$ ). A, D, G, J = dorsal view; B, E, H, K = ventral view; C, F, I, L = lateral view. 


\section{Material examined}

VIETNAM: 1 早 (Figs 6A-C, 7) [Coll. I.R.Sc.N.B., Vietnam, Hanoi pr., BaVi N.P., 21 ${ }^{\circ} 4^{\prime} 4^{\prime \prime} \mathrm{N}$ 105²1'30" E, 25-29.vi.2015 day collecting, Leg. J. Constant \& J. Bresseel, I.G.:33.092] (RBINS); 1 \& (Fig. 6D-F), same data (RBINS); 1 \& (Fig. 6G-I) [Vietnam, Da Krong Nat. R., Quang Tri prov.

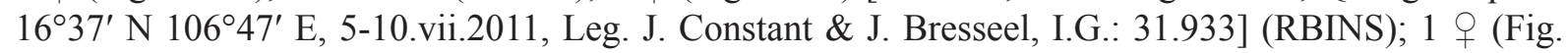
6J-L) [Vietnam, Lam Dong, Bi Doup massif, Da Lat, Ghang Ly, 1467m, 12¹1.052' N 108 $40.669^{\prime}$ E] [Museum Paris, 12-VI-2008, beating, open range \& forest edge, Th. Bourgoin réc.] [Museum Paris, MNHN (EH) 22873] [Gergithoides sp. Gnezdilov det. 2014] (MNHN).

This specimen was mentioned by Gnezdilov et al. (2014).

\section{Gergithoides carinatifrons Schumacher, 1915}

Gergithoides carinatifrons Schumacher, 1915: 126.

Daruma nitobei Matsumura, 1916: 103 (synonymised by Ishihara 1965a).

Gergithoides carinatifrons - Esaki 1932: 1795 (described), fig. 1 (illustrated). — Kato 1933: pl. 4, fig. 1 (illustrated). - Metcalf 1958: 120 (catalogued). - Ishihara 1965a: 208 (senior synonym of Daruma nitobei Matsumura, 1916 (misspelled Darma nitobei), recorded from Japan). — Ishihara 1965b: 131 (listed), pl. 66, fig. 6 (illustrated - specimen from Shikoku, Japan). - Hori 1969: 62 (records from Japan), figs 2, 5-7 (frons, clypeus and male genitalia illustrated), pls 2, 7-8 (habitus illustrated). Chan \& Yang 1994: 17 (described; male genitalia), fig. 5 (wings, frons and clypeus, vertex, proand mesonotum, and male genitalia, illustrated). - Che et al. 2003: 103 (keyed; recorded from Hainan, in Chinese), 107 (recorded from Hainan, in English). - Gnezdilov 2009: 85 (notes on type specimens; records from Taiwan; senior synonym of Daruma nitobei), figs 5-6 (dorsal and frontal view of specimen from Taiwan). - Sun et al. 2012: 50 (compared with Neogergithoides tubercularis Sun, Meng \& Wang, 2012), figs 43-45 (illustrated). — Rahman et al. 2012: 295 (keyed). - Chen et al. 2014: 37 (keyed, described, recorded from Guizhou, in Chinese; distribution map), fig. 2-6

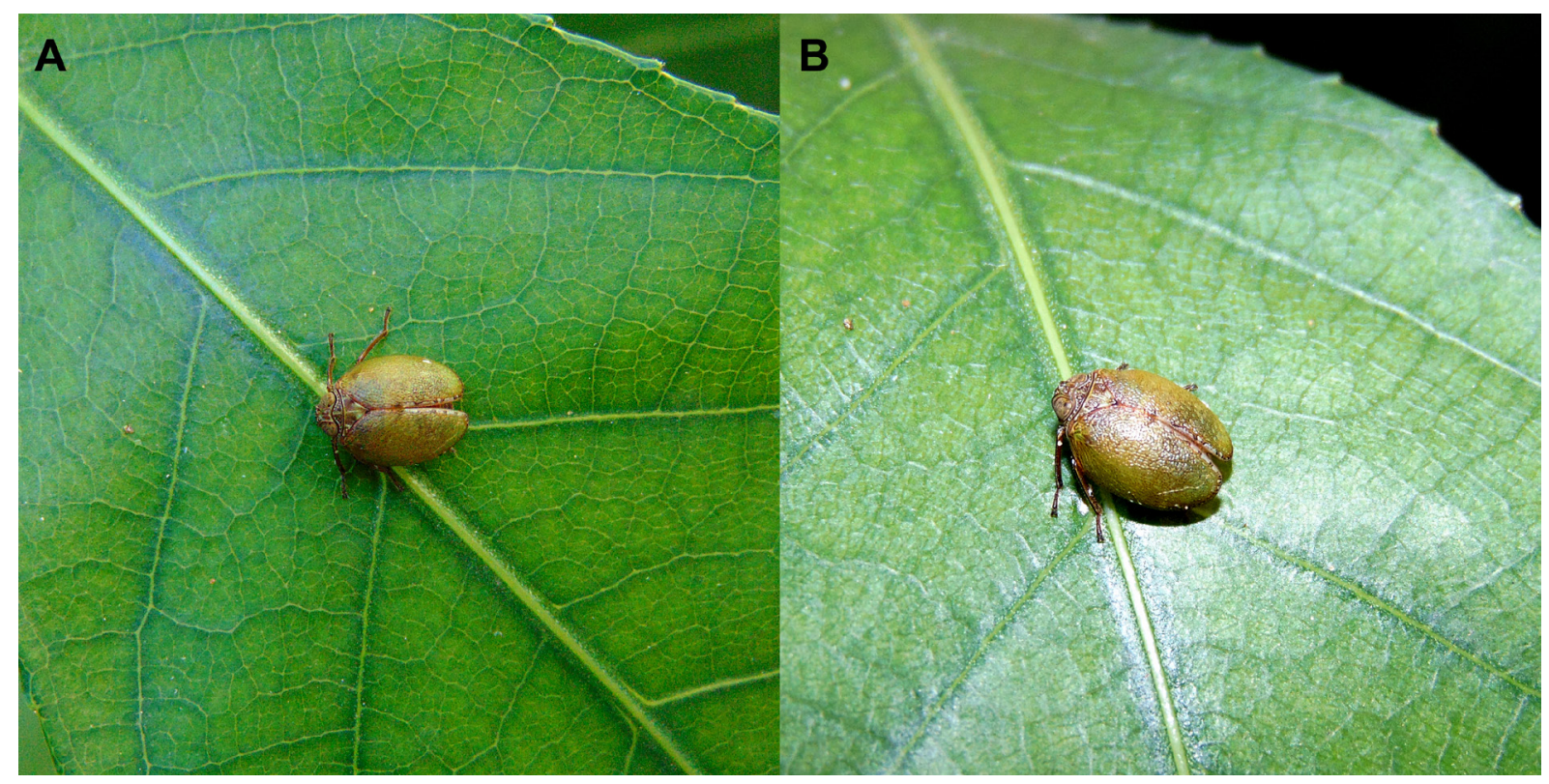

Fig. 7. Gergithoides +, unidentified species from Ba Vi National Park. A-B. Live specimen, 29 Jun. 2015 (photographs (C) J. Constant - RBINS). 
(habitus, details and male genitalia illustrated - photographs of specimen from Guizhou, drawings reproduced from Chan \& Yang 1994), 187 (recorded from Guizhou, in English).

Darumara nitobei - Metcalf 1952: 227 (Darumara = replacement name for Daruma). - Metcalf 1958: 158 (catalogued). — Chan \& Yang 1994: 20 (described).

non Gergithoides carinatifrons - Kwon \& Huh 1995: 40 (recorded from South Korea (based on misidentification, see Rahman et al. 2012)). - Kwon \& Huh 2001: 310 (listed from South Korea, based on misidentification, see Rahman et al. 2012).

\section{Remarks}

This species was described based on two specimens from Taiwan by Schumacher (1915), together with one variety, G. carinatifrons var. uniformis Schumacher, 1915. Unfortunately, the syntypes of $G$. carinatifrons are destroyed (only one hind wing still exists, see Gnezdilov 2009), but the species was redescribed by Chan \& Yang (1994) based on specimens from Taiwan. It was also mentioned from Japan (Ishihara 1965a, 1965b; Hori 1969), China (Che et al. 2003; Chen et al. 2014), and South Korea (Kwon \& Huh 1995, 2001).

South Korean specimens were checked by Rahman et al. (2012), who found them to belong to another species which they described as G. jejudoensis Rahman, Kwon \& Suh, 2012. Considering this wrong record of G. carinatifrons in South Korea, it remains questionable if the species is present in Japan. Indeed, the male genitalia represented in Hori's (1969) publication do not match the drawings of Chan \& Yang (1994), but it is unclear if these authors used a specimen from Taiwan (where there might be more than one Gergithoides species) or from Japan, and this requires further investigation.

The presence of the species in China (Hainan), reported by Che et al. (2003) is probably based on misidentified specimens, as the characters extrapolated from their identification key (tegmina dark brown with black marking - S. Chen pers. comm. Sep. 2016) do not match the illustration of a Taiwan specimen of G. carinatifrons provided by Gnezdilov (2009).

The Guizhou (China) specimens identified as G. carinatifrons and G. rugulosus mentioned and illustrated by Chen et al. (2014) belong to the same collecting event: Xiaodanjiang, Leigongshan, Guizhou, 16 Sep. 2005. The genitalia illustrations for G. carinatifrons in Chen et al. (2014) are reproduced from Chan \& Yang (1994). The specimens of G. carinatifrons and G. rugulosus illustrated in Chen et al. (2014) are probably conspecific and belong to a species characterized by the male genitalia illustrated under the name G. rugulosus in their book. However, this taxon is most likely neither $G$. carinatifrons nor G. rugulosus, and it represents an undescribed species.

Finally, the Chinese specimen of G. carinatifrons illustrated and described by comparison with Neogergithoides tubercularis Sun, Meng \& Wang, 2012 by Sun et al. (2012) does not match Gnezdilov's (2009) description and it belongs to another species. Unfortunately, Sun et al. (2012) failed to mention the origin of the illustrated specimen they attributed to G. carinatifrons.

As a conclusion, we consider that the presence of G. carinatifrons outside Taiwan still needs to be confirmed by the examination of male genitalia.

\section{Gergithoides rugulosus (Melichar, 1906)}

Fig. 8

Gergithus rugulosus Melichar, 1906: 64. 


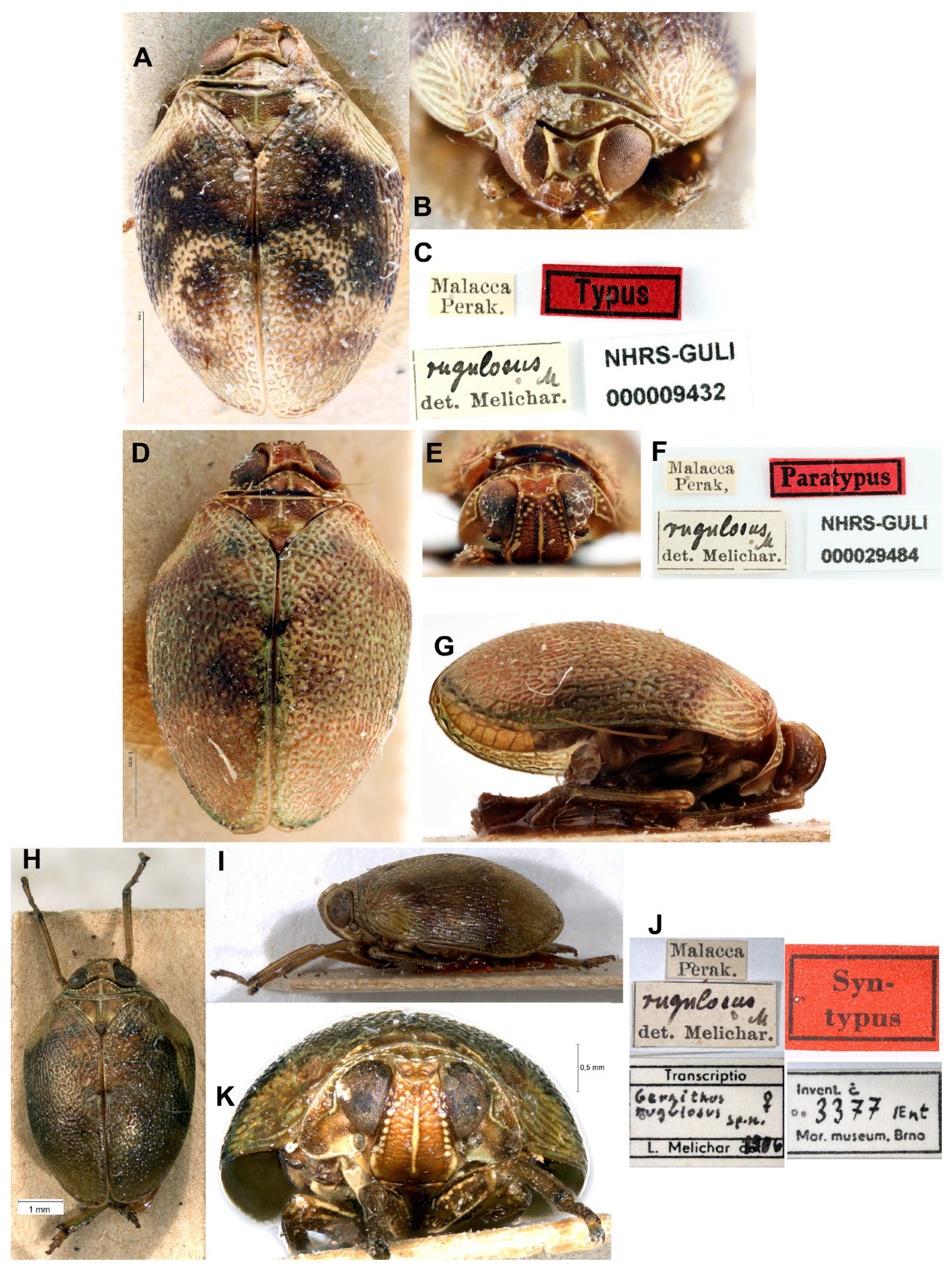

Fig. 8. Gergithoides rugulosus Melichar, 1906, syntypes. A-C. Male syntype in NHRS (photographs $($ ) G. Lindberg - NHRS). D-G. Female syntype in NHRS (photographs (C) G. Lindberg - NHRS). H-K. Female syntype in MMBC (photographs $($ I. Malenovsky - MMBC). A, D, H. Dorsal views. B. Head and thorax, dorsal view. C, F, J. Labels. E, K. Frontal views. G, I. Lateral views. 
Gergithoides rugulosus - Jacobi 1944: 19 [transferred to Gergithoides; recorded from China (Fujian)]. Metcalf 1958: 120 [catalogued]. — Che et al. 2003: 103 [keyed, recorded from Fujian, Guangxi, Sichuan and Yunnan (in Chinese)], 107 [recorded from Fujian, Guangxi, Sichuan and Yunnan (in English)]. Rahman et al. 2012 [keyed]. — Gnezdilov et al. 2014: 93 [note]. — Chen et al. 2014: 37 [keyed (in Chinese)], 38 [distribution map], fig. 2-9 [habitus, details and male genitalia illustrated], 43 [described, recorded from Guizhou (in Chinese)], 188 [distribution, recorded from Guizhou (in English)].

\section{Type material examined}

MALAYSIA: Syntypes of Gergithus rugulosus (examined on photographs, Fig. 8): 1 त [Malacca, Perak] [rugulosus M det. Melichar] [Typus] [NHRS-GULI 000009432] (NHRS); 1 + [Malacca, Perak] [rugulosus M det. Melichar] [Paratypus] [NHRS-GULI 000029484] (NHRS); 1 q [Malacca, Perak] [rugulosus M det. Melichar] [Syn-typus] [transcriptio Gergithus rugulosus sp. n. + , L. Melichar 1906] [Invent. č 3377 / Ent, Mor. Museum, Brno] (MMBC).

\section{Remarks}

This species was described based on 3 syntype specimens (Fig. 8) from southern Malaysia. The genitalia of the male syntype were not illustrated to date.

The species was later mentioned from China: from Fujian by Jacobi (1944), from Guangxi, Sichuan and Yunnan by Che et al. (2003), and from Guizhou by Chen et al. (2014).

Male genitalia attributed to the species were illustrated by Chen et al. (2014) based on a male specimen from Guizhou. It seems worth mentioning that the specimens from Guizhou are from the same collecting event as female specimens attributed by Chen et al. (2014) to another species, G. carinatifrons, and illustrated as such (see comments under G. carinatifrons). We consider that the specimens illustrated as G. rugulosus and G. carinatifrons by Chen et al. (2014) are actually conspecific and should represent a new species.

Subsequently, the presence of G. rugulosus in China remains highly questionable. This issue needs to be solved by the study of the genitalia of the male syntype of G. rugulosus.

Gergithoides undulatus Wang \& Che, 2003

Gergithoides undulatus Wang \& Che, 2003 in Che et al. 2003: 103 [keyed, described (in Chinese)], figs 1-6 [frons, vertex, pro- and mesonotum, tegmen and male genitalia illustrated], 107 [diagnosis in English].

Gergithoides undulatus - Rahman et al. 2012: 295 [keyed]. — Chen et al. 2014: 37 [keyed (in Chinese)], 38 [distribution map], fig. 2-10 [habitus, details and male genitalia illustrated], 43 [described, recorded from Hainan (in Chinese)]; 188 [distribution, recorded from Hainan (in English)].

\section{Remarks}

This species was described by Che et al. (2003) based on the male holotype from Guangxi and 10 female paratypes from Hainan. As no male from Hainan was examined to support the attribution of the series of female paratypes by the authors, the consistency of the type series of $G$. undulatus remains questionable.

The specimen and male genitalia illustrated in Chen et al. (2014) are based on material from Hainan and do not match the illustrations provided in the original description. Particularly, and compared to the latter, the following differences can be observed in the specimen from Hainan: (1) vertex more elongate, 
(2) anal tube with posterior margin roundly emarginate, not bisinuate, and without ante-apical strong constriction, and (3) gonostyli more elongate.

Hence, the presence of the species in Hainan still requires confirmation by the examination of male genitalia.

\section{Discussion}

The taxonomic and biogeographical conclusions of this study are:

- G. carinatifrons is currently restricted to Taiwan, is not present in South Korea and its distribution on the Chinese mainland and Japan still needs confirmation.

- G. rugulosus is currently restricted to Malaysia and its distribution in China still needs confirmation.

- G. undulatus is currently restricted to the Chinese mainland and its distribution in Hainan still needs confirmation.

- G. carinatifrons and G. rugulosus from Guizhou (China), as reported in Chen et al. (2014), are conspecific and belong to another, undescribed species

- G. undulatus from Hainan (China), currently known from female specimens only, are moved to a new, undescribed species. Males from the type locality are needed before initiating the description of this new taxon.

The present paper illustrates a common problem in the study of Fulgoromorpha and notably of smallsized taxa which require examination of male genitalia characters for specific identification: the lack of material, especially of male specimens, which sometimes leads to inaccurate species attribution. Recent issid studies (see, e.g., Gnezdilov 2015; Constant \& Pham 2016) have shown that critical treatment of specimens and data are extremely important to support biodiversity and biogeographical hypotheses.

For these reasons, two new species are here described while 3-4 more are waiting for the collecting of a male specimen. We decided to illustrate those species to attract the attention of other workers to them, who might possess or collect additional material.

Natural history, host-plants and nymphal development are as yet undocumented for species of Gergithoides.

The tribe Hemisphaeriini in Vietnam now counts 6 genera with 21 described species (Gnezdilov et al. 2014; Constant \& Pham 2014, 2015, 2016).

\section{Acknowledgments}

We thank Mr Joachim Bresseel (collaborator, RBINS) and Mr Vu Tru Hoang (Insitute of Ecology and Biological Resources, Hanoi, Vietnam) for their help and permanent enthusiasm during our collecting trips in Vietnam, Pr. Thierry Bourgoin (Muséum national d'Histoire naturelle, Paris, France) for his constant cooperation and critical review of the manuscript, and Mrs Gunvi Lindberg (NHRS), Dr Igor Malenovsky (MMBC), Dr Masami Hayashi (Chigasaki, Japan), Dr Vladimir Gnezdilov (Zoological Institute, Russian Academy of Sciences, St. Petersburg, Russia) and Mr Suede Chen (Taipei, Taiwan) for their help with photographs, papers and/or translations. The authors' collecting trips were supported through a grant issued by the capacity building Programme of the Belgian Global Taxonomic Initiative National Focal Point that runs under the CEBioS programme with financial support from the Belgian Directorate-General for Development Cooperation (DGD). The present study was 
partially supported by the National Foundation for Science and Technology Development, Vietnam (NAFOSTED-106.12-2012.63) and by IDEA WILD, who donated equipment to the second author.

\section{References}

Bourgoin T. 2016. FLOW (Fulgoromorpha Lists on The Web): A World Knowledge Base Dedicated to Fulgoromorpha. V.8, updated [15 Sept. 2016]. Available from http://hemiptera-databases.org/flow/ [accessed 15 Sep. 2016].

Carayon J. 1969. Emploi du noir chlorazol en anatomie microscopique des insectes. Annales de la Société entomologique de France (N.S.) 5: 179-193.

Chan M.-L. \& Yang C.-T. 1994. Issidae of Taiwan (Homoptera: Fulgoroidea). National Chung Hsing University, Department of Entomology, Taichung (Taiwan).

Che Y.-L., Wang Y.-L. \& Chou I. 2003. Taxonomic study on the genus Gergithoides Schumacher (Homoptera: Fulgoroidea: Issidae). Entomotaxonomia 25 (2): 102-108 [in Chinese].

Chen X.-S., Zhang Z.-G. \& Chang Z. 2014. Issidae and Caliscelidae from China. Guizhou Science and Technology Publishing House, Guiyang.

Constant J. 2004. Révision des Eurybrachidae (I). Le genre Amychodes Karsch, 1895 (Homoptera: Fulgoromorpha: Eurybrachidae). Bulletin de l'Institut royal des Sciences naturelles de Belgique 74: $11-28$.

Constant J. \& Pham H.T. 2014. A new species of Macrodaruma Fennah, 1978 from Northern Vietnam (Hemiptera: Fulgoromorpha: Issidae). Belgian Journal of Entomology 22: 1-8.

Constant J. \& Pham H.T. 2015. Two new species of the genus Neogergithoides Sun, Meng \& Wang, 2012 extend its distribution to Northern Vietnam (Hemiptera: Fulgoromorpha: Issidae). Belgian Journal of Entomology 33: 1-15.

Constant J. \& Pham H.T. 2016. Maculergithus, a new subgenus in Gergithus Schumacher, 1915 with two new species from northern Vietnam (Hemiptera: Fulgoromorpha: Issidae). European Journal of Taxonomy 198: 1-16. https://doi.org/10.5852/ejt.2016.198

Esaki T. 1932. Nippon Konchu Zukan. Iconographia Insectorum Japonicorum. Hokuryukan, Tokyo

Gnezdilov V.M. 2009. Revisionary notes on some tropical Issidae and Nogodinidae (Hemiptera: Fulgoroidea). Acta Entomologica Musei Nationalis Pragae 49 (1): 75-92.

Gnezdilov V.M. 2015. A new species of the genus Tetricodes Fennah (Hemiptera: Fulgoroidea: Issidae) from southern China. Entomotaxonomia 37 (1): 27-30.

Gnezdilov V.M., Bourgoin T. \& Soulier-Perkins A. 2014. Vietnamese Issidae (Hemiptera, Fulgoroidea): new taxa, new records and new distribution data. Zootaxa 3847 (1): 80-96. https://doi.org/10.11646/ zootaxa.3847.1.4

Hori Y. 1969. Hemisphaeriinae of the Japan Archipelago (Hemiptera: Issidae). Transactions of the Shikoku Entomological Society 10 (2): 49-66.

Ishihara T. 1965a. Some species of Formosan Homoptera. Special Bulletin of the Lepidoptera Society of Japan 1: 201-221.

Ishihara T. 1965b. Iconographia Insectorum Japonicorum, Colore Naturali Edita, vol. III. HokuryuKan Publishing Co. Ltd, Tokyo.

Jacobi A. 1944. Die Zikadenfauna der Provinz Fukien in Südchina und ihre tiergeographischen Beziehungen. Mitteilungen der Münchner Entomologischen Gesellschaft 34: 5-66. 
Kato M. 1933. Homoptera. Three Colour Illustrated Insects of Japan 4: 1-13.

Kwon Y.J. \& Huh E.Y. 1995. A check list of the Auchenorrhyncha from Chejudo (Homoptera). Insecta Koreana (Supplement) 5: 19-54.

Kwon Y.J. \& Huh E.Y. 2001. Suborder Auchenorrhyncha. Economic Insects of Korea 19. Insecta Koreana (Supplement) 26: 308-312.

Matsumura S. 1916. Synopsis der Issiden (Fulgoriden) Japans. Transactions of the Sapporo Natural History Society 6: 85-118.

Metcalf Z.P. 1952. New names in the Homoptera. Journal of the Washington Academy of Sciences 42: 226-231.

Metcalf Z.P. 1958. Fascicle IV, Fulgoroidea. Part 15. Issidae. In: Metcalf Z. P. (ed.) General Catalogue of the Homoptera. Fascicule IV. North Carolina State College, Raleigh.

Rahman M.A., Kwon Y.J. \& Suh S.J. 2012. A new species of the genus Gergithoides Schumacher (Hemiptera: Fulgoroidea: Issidae) from Korea. Entomological News 122 (4) [2011]: 293-299. https:// doi.org/10.3157/021.122.0401

Schumacher F. 1915. Der gegenwärtige Stand unserer Kenntnis von der Homopteren-Fauna der Insel Formosa. Mitteilungen aus dem Zoologischen Museum in Berlin (8): 73-134. Available from http:// biodiversitylibrary.org/page/30243518 [accessed 6 Mar. 2017].

Sun Y., Meng R. \& Wang Y. 2012. Neogergithoides, a new genus with a new species from China (Hemiptera: Issidae). Zootaxa 3186: 42-53.

Wang Meng-Lin, Zhang Ya-Lin \& Bourgoin T. 2016. Planthopper family Issidae (Insecta: Hemiptera: Fulgoromorpha): linking molecular phylogeny with classification. Molecular Phylogenetics and Evolution 105: 224-234. https://doi.org/10.1016/j.ympev.2016.08.012

Manuscript received: 21 October 2015

Manuscript accepted: 19 December 2016

Published on: 10 March 2017

Topic editor: Koen Martens

Desk editor: Kristiaan Hoedemakers

Printed versions of all papers are also deposited in the libraries of the institutes that are members of the EJT consortium: Muséum national d'Histoire naturelle, Paris, France; Botanic Garden Meise, Belgium; Royal Museum for Central Africa, Tervuren, Belgium; Natural History Museum, London, United Kingdom; Royal Belgian Institute of Natural Sciences, Brussels, Belgium; Natural History Museum of Denmark, Copenhagen, Denmark; Naturalis Biodiversity Center, Leiden, the Netherlands. 